\title{
Relaxin induces rapid, transient vasodilation in the microcirculation of hamster skeletal muscle
}

\author{
Jordan M Willcox ${ }^{1}$, Alastair J S Summerlee ${ }^{1}$ and Coral L Murrant ${ }^{2}$
}

Departments of ${ }^{1}$ Biomedical Sciences and ${ }^{2}$ Human Health and Nutritional Sciences, University of Guelph, ANNU Bldg, Room 350, Guelph, Ontario, Canada N1G 2W1
Correspondence should be addressed to C L Murrant Email cmurrant@uoguelph.ca

\begin{abstract}
Relaxin produces a sustained decrease in total peripheral resistance, but the effects of relaxin on skeletal muscle arterioles, an important contributor to systemic resistance, are unknown. Using the intact, blood-perfused hamster cremaster muscle preparation in situ, we tested the effects of relaxin on skeletal muscle arteriolar microvasculature by applying $10^{-10} \mathrm{M}$ relaxin to second-, third- and fourth-order arterioles and capillaries. The mechanisms responsible for relaxin-induced dilations were explored by applying $10^{-10} \mathrm{M}$ relaxin to second-order arterioles in the presence of $10^{-5} \mathrm{M} \mathrm{N}(\mathrm{G})$-nitro-L-arginine methyl ester (L-NAME, nitric oxide (NO) synthase inhibitor), $10^{-5} \mathrm{M}$ glibenclamide (GLIB, ATP-dependent potassium $\left(\mathrm{K}^{+}\right)$ channel inhibitor), $10^{-3} \mathrm{M}$ tetraethylammonium (TEA) or $10^{-7} \mathrm{M}$ iberiotoxin (IBTX, calcium-associated $\mathrm{K}^{+}$channel inhibitor). Relaxin caused second- (peak change in diameter: $8.3 \pm 1.7 \mu \mathrm{m})$ and third $(4.5 \pm 1.1 \mu \mathrm{m})$-order arterioles to vasodilate transiently while fourth-order arterioles did not $(0.01 \pm 0.04 \mu \mathrm{m})$. Relaxin-induced vasodilations were significantly inhibited by L-NAME, GLIB, TEA and IBTX. Relaxin stimulated capillaries to induce a vasodilation in upstream fourth-order arterioles $(2.1 \pm 0.3 \mu \mathrm{m})$, indicating that relaxin can induce conducted responses vasodilation that travels through blood vessel walls via gap junctions. We confirmed gap junction involvement by showing that gap junction uncouplers (18- $\beta$-glycyrrhetinic acid $\left(40 \times 10^{-6} \mathrm{M}\right)$ or $0.07 \%$ halothane) inhibited upstream vasodilations to localised relaxin stimulation of second-order arterioles. Therefore, relaxin produces transient NO- and $\mathrm{K}^{+}$channel-dependent vasodilations in skeletal muscle arterioles and stimulates capillaries to initiate conducted responses. The transient nature of the arteriolar dilation brings into question the role of skeletal muscle vascular beds in generating the sustained systemic haemodynamic effects induced by relaxin.
\end{abstract}
Key Words
- relaxin
- vasodilation
- skeletal muscle
- arteriole
- capillary

Journal of Endocrinology (2013) 218, 179-191

\section{Introduction}

Recently, interest has been generated concerning the effects of the peptide hormone relaxin in the cardiovascular system, as numerous clinical trials are proceeding using relaxin as a therapeutic to treat acute human heart failure (Teerlink et al. 2009, Metra et al. 2010, Teichman et al. 2010). In spite of the recent progression of clinical trials, our understanding of the effects of relaxin in the cardiovascular system remains incomplete. Skeletal muscle resistance arterioles play a critical role in the regulation of systemic vascular resistance (Haddy et al. 1968, Folkow et al. 1984), and relaxin has been demonstrated to elicit vasodilation in renal (Danielson et al. 
1999) and mesentery vascular beds (Bigazzi et al. 1986) and rapid relaxin-induced relaxation of isolated resistance arterioles (Fisher et al. 2002, McGuane et al. 2011). Therefore, given the important contribution of skeletal muscle resistance arterioles to systemic vascular resistance and the potential for relaxin to promote vasodilation, it is critical to examine the putative vasodilatory effects of relaxin in the skeletal muscle microvasculature in order to understand the systemic haemodynamic effects of relaxin.

In this study, we used an in situ model where blood vessels can be visualised in a live, intact preparation, the anaesthetised, blood-perfused hamster cremaster muscle preparation, to test the vasodilatory effects of relaxin on skeletal muscle arteriolar reactivity. The hamster cremaster muscle preparation is a common model for skeletal muscle microcirculation (for example, see Baez (1973), Gorczynski et al. (1978), Meininger (1987), Hester et al. (1993), Jackson (1993), Berg et al. (1997) and Armstrong et al. (2007)). This model is a good templar for the study of skeletal muscle microcirculation because it is of mixed fibre types similar to human muscle (Sarelius et al. 1983), the muscle is thin and the entire intact arteriolar network can be directly visualised using intravital microscopy, drugs can be applied directly to the arteriole of interest without affecting the entire animal and the vasculature remains within its native tissue with all the neural, humoral and locally released tissue factor influences intact.

The aims of this study were threefold: i) the first was to determine the vasoactive actions of relaxin in the arteriolar microcirculation of skeletal muscle. Previous studies have shown that relaxin stimulates vasodilation through nitric oxide (NO)-mediated mechanisms (Bani-Sacchi et al. 1995, Danielson \& Conrad 1995, Bani et al. 1998, Danielson et al. 1999, McGuane et al. 2011); therefore, we investigated this possibility in relaxin-induced responses in skeletal muscle arterioles. Furthermore, relaxin has been shown to alter smooth muscle function through the modulation of potassium channels (Anwer et al. 1993, Meera et al. 1995, PiedrasRenteria et al. 1997); thus, we investigated this possibility in skeletal muscle resistance arterioles. ii) The second was to determine whether different branch orders of the terminal microvasculature respond similarly to relaxin. It has been demonstrated that terminal arterioles are less influenced by NO than are larger arterioles (Hester et al. 1993); thus, relaxin's effect may not be equal among different branch orders of resistance arteriole. iii) The third was to determine whether capillaries can be stimulated by relaxin. Capillaries have been identified as a locus of control of blood flow in skeletal muscle (Berg et al. 1997, Twynstra et al. 2012). Stimulation of capillaries can cause signals to be sent proximally through the blood vessel wall, via gap junctions, to the upstream arterioles controlling resistance and flow through the stimulated capillaries (for review see Segal (2005)). Communication of gap junction-dependent signals from local vascular sites to remote upstream vascular sites are known as conducted responses (Segal \& Duling 1986, 1989). Capillary stimulation by relaxin will indicate whether relaxin can alter arteriolar diameter by inducing conducted responses.

\section{Materials and methods}

\section{Animals}

All surgical and experimental procedures were approved by the Animal Care Committee of the University of Guelph and were completed in accordance with the guidelines of the Canadian Council on Animal Care set out in the Guide to the Care and use of Experimental Animals. Adult male Golden Syrian Hamsters (100-130 g) were purchased from Charles River (Saint-Constant, QC, Canada). Animals had access to food and water ad libitum and were housed in a $14 \mathrm{~h}$ light:10 h darkness cycle.

\section{General surgical procedures}

Hamsters were initially anaesthetised with sodium pentobarbital $(70 \mathrm{mg} / \mathrm{kg}$ i.p.) and tracheotomised. Polyetheylene catheters were placed in the left femoral vein (for supplemental pentobarbital during surgery) and in the left femoral artery to monitor mean arterial pressure (to confirm a stable plain of anaesthesia). Hamsters were placed on a lucite platform fitted with water-filled heating coils to maintain an oesophageal temperature of $37^{\circ} \mathrm{C}$. The right cremaster muscle was prepared for in situ microscopy by procedures first described by Baez (1973) and modified by Murrant (2005). Briefly, the right testis was isolated and skin was cut longitudinally, exposing the cremaster muscle. The muscle and scrotum were separated and cleaned of connective tissue; the cremaster muscle was cut longitudinally, separated from the testis and epididymis, and spread over a semi-circular lucite platform. The periphery of the muscle was fixed to the platform by insect pins; care was taken not to stretch the muscle. The exposed muscle was constantly superfused with a bicarbonate-buffered physiological salt solution containing (mmol/l) $\mathrm{NaCl} 131.9, \mathrm{KCl} 4.7, \mathrm{CaCl}_{2} 2.0$, $\mathrm{MgSO}_{4}$ 1.2, $\mathrm{NaHCO}_{3} 30$ (Fisher Scientific, Ottawa, ON,

Published by Bioscientifica Ltd 
Canada) and $0.3 \mathrm{mg} / \mathrm{l}$ tubarine. The solution was equilibrated with $5 \% \mathrm{CO}_{2}-95 \% \mathrm{~N}_{2}$ gas and final $\mathrm{pH}$ was 7.35-7.45. The drip rate of the superfusate was adjusted to maintain a cremaster muscle temperature of $34^{\circ} \mathrm{C}$. The preparation was then moved to the intravital microscope and allowed to equilibrate for $45-60 \mathrm{~min}$ before the start of the experimental protocols. During all experimental protocols, pentobarbital sodium $(10 \mathrm{mg} / \mathrm{ml}$ saline; $0.56 \mathrm{ml} / \mathrm{h}$; i.v.) was constantly administered via an anaesthetic pump.

The microvasculature of the cremaster muscle was visualised with an Olympus BX51WI microscope (Olympus Canada, Inc., Richmond Hill, ON, Canada) using a $\times 20$ long objective (n.a. 0.50 ) and a $\times 1.6$ magnification changer and transilluminated by a tungsten lamp. The resulting images were recorded using a video camera (DXC-390; Sony Canada Ltd., Toronto, ON, Canada) displayed on a monitor and recorded using a videotape recorder (Sony, SVO-9600 MD). Final magnification of the selected site was approximately $\times 2000$. Data were recorded on videocassettes (Sony, T-120PR) and analysed off-line using calibrated ImageJ software (public domain software, http://rsb.info.nih.gov, NIHMH, Bethesda, MD, USA).

\section{Application of relaxin in experimental protocols}

As relaxin- 2 is the circulating and biologically significant form of relaxin in humans, we used recombinant human relaxin-2 in our studies. In humans, relaxin- 2 acts in a similar fashion to relaxin-1 (the biologically active form in rodents). Furthermore, relaxin-3 appears to act primarily as a neuropeptide and there is no evidence that relaxin-3 circulates in the body; therefore, relaxin- 3 was not studied (Bathgate et al. 2006).

Relaxin was applied to the cremaster preparation either globally over the whole preparation through the superfusate or to specific localised vascular sites using glass micropipettes. Glass tubes were pulled using a pipette puller (PC-10; Narishige International USA, Inc., East Meadow, NY, USA) and bevelled (BV-10; Sutter Instrument Co., Novato, CA, USA) (tip diameter $\sim 10 \mu \mathrm{m}$ ). Micropipettes were filled with pharmacological agents or relaxin $\left(10^{-10} \mathrm{M}\right)$ and FITC-dextran $\left(10^{-4} \mathrm{M}\right.$, FITC $)$ as a marker for micropipette flow. Previous studies have confirmed that $10^{-4} \mathrm{M}$ FITC is not vasoactive (Frame \& Sarelius 1993). The micropipette tip was positioned close to the test arteriole using a micromanipulator. The micropipette was connected to a water manometer and water pressure was adjusted to cause drugs in the pipette to flow onto the test site (Frame \& Sarelius 1993). Epifluorescence was used

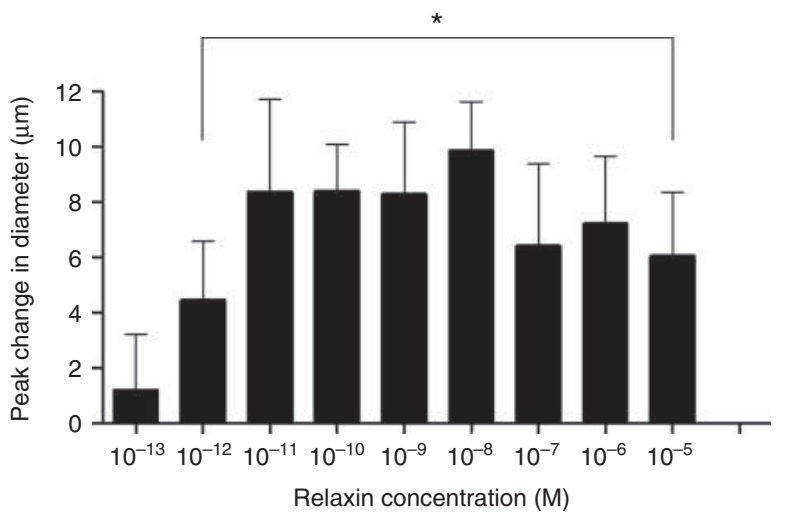

Figure 1

The peak change in diameter of the TA in response to incremental doses of relaxin. Two dose response experiments were conducted: i) $10^{-10}$ to $10^{-5} \mathrm{M}(n=5)$ and ii) $10^{-13}$ to $10^{-8} \mathrm{M}(n=6)$. Data from both series of dose response experiments were combined to produce a dose-response curve (total 11 animals; i.e. $10^{-13}$ to $10^{-11} \mathrm{M}(n=6), 10^{-10}$ to $10^{-8} \mathrm{M}(n=11)$, $10^{-7}$ to $\left.10^{-5} \mathrm{M}(n=5)\right)$. *Significantly different values from baseline.

to confirm flow from the micropipette and that flow from the micropipette was approximately perpendicular to the arteriole under investigation and that no other parts of the vasculature under investigation were being exposed. The region of the arteriole that was exposed during micropipette application was $\sim 200 \mu \mathrm{m}$. Figure $2 \mathrm{~A}$ shows a schematic representation of the terminal arteriolar microvasculature architecture under study, whereby blood flows through a subsequently diverging network of arterioles from the paired feed arterioles through the transverse (TA), Branch and module inflow arterioles (MI) until it reaches the capillary module of the network.

\section{Experimental protocol 1: relaxin dose response}

To determine the reactivity of the microvasculature to relaxin, we performed an initial dose response of $10^{-10}$ to $10^{-5} \mathrm{M}(n=5)$ relaxin (from lowest to highest concentration), globally applied to the entire cremaster preparation while observing a TA. Relaxin induced vasodilation at the lowest concentration tested; therefore, a second protocol was performed using $10^{-13}$ to $10^{-8} \mathrm{M}$ relaxin $(n=6)$. During the experimental protocol, TA diameter was continuously recorded for $1 \mathrm{~min}$ before relaxin application (to obtain a baseline diameter value) and then continuously for each subsequent 5 -min relaxin application. We observed a non-significant dilation at $10^{-13} \mathrm{M}$, and what appeared to be a maximal response at $10^{-10} \mathrm{M}$. Thus, we chose to use $10^{-10} \mathrm{M}$ relaxin for the rest of the experimental protocols.

Published by Bioscientifica Ltd. 


\section{Experimental protocol 2: effects of $10^{-10} \mathrm{M}$ relaxin on specific arteriolar branch orders}

MIs (fourth-order arterioles), Branches (third-order arterioles) and TAs (second-order arterioles) were identified by counting up one, two or three branch order from the capillaries respectively (nomenclature based on that of Berg et al. (1997), see Fig. 2A). Arteriolar diameter at the TA, Branch or MI observation site was continuously recorded for $1 \mathrm{~min}$ before relaxin exposure and then continuously during the 5-min micropipette application of $10^{-10} \mathrm{M}$ relaxin. Multiple branch orders were tested per
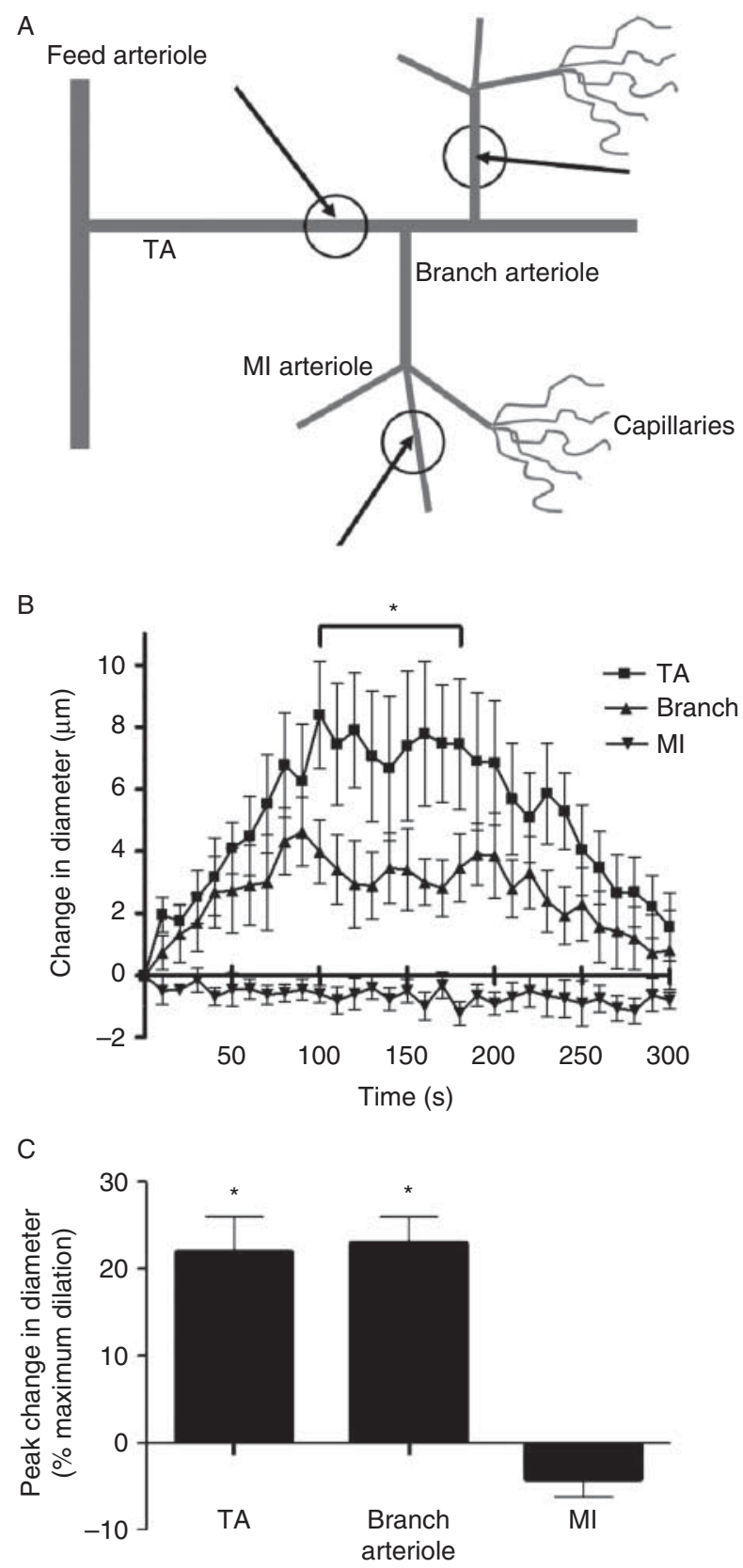

http://joe.endocrinology-journals.org DOI: $10.1530 / J O E-13-0115$ preparation and care was taken to ensure that each branch order tested was not a vessel from the same terminal microvasculature network previously tested.

\section{Experimental protocol 3: involvement of $\mathrm{NO}$ and potassium channels in the relaxin-mediated vasodilation}

TA diameter was recorded for $1 \mathrm{~min}$ before relaxin application and throughout the $5 \mathrm{~min}$ of superfusion of $10^{-10} \mathrm{M}$ relaxin (control). Preparations were then superfused with known pharmacological inhibitors of $\mathrm{NO}$ synthase $(N(\mathrm{G})$-nitro-L-arginine methyl ester (L-NAME); $10^{-5} \mathrm{M}$ ) (Murrant \& Sarelius 2002, Dua et al. 2009) or inhibitors of potassium channels, ATP-dependent potassium $\left(\mathrm{K}_{\mathrm{ATP}}\right)$ channel inhibitor glibenclamide (GLIB; $10^{-5} \mathrm{M}$ ) (Murrant \& Sarelius 2002) or calcium-associated potassium $\left(\mathrm{K}_{\mathrm{Ca}}\right)$ channel inhibitor iberiotoxin (IBTX; $10^{-7} \mathrm{M}$ ) (Jackson \& Blair 1998) or tetraethylammonium (TEA) $\left(10^{-3} \mathrm{M}\right)$ (Jackson \& Blair 1998). Experiments involving L-NAME application produced significant arteriolar vasoconstriction presumably due to the inhibition of endogenous NO production. Thus, when using L-NAME, we also added S-nitroso- $N$-acetylpenicillamine $\left(10^{-7} \mathrm{M}\right.$, SNAP), an NO donor, in order to restore the basal levels of endogenous NO and maintain a baseline arteriolar diameter similar to control values. L-NAME + SNAP, GLIB and IBTX were superfused for $30 \mathrm{~min}$ while TEA was superfused for $1 \mathrm{~h}$. Relaxin $\left(10^{-10} \mathrm{M}\right)$ was then re-applied for $5 \mathrm{~min}$ in the presence of the inhibitors and arteriolar diameter was recorded as described earlier. Inhibitors were then

\section{Figure 2}

The vasodilatory response to relaxin applied directly to different branch orders of the arteriolar network. (A) A schematic representation of the branches of the terminal arteriolar microvasculature (diagram adapted from Murrant \& Sarelius (2000)). Blood flows through a subsequently diverging network of arterioles from the paired feed arterioles through the TA, Branch and MI arterioles until it reaches the capillary modules of the network. The schematic is not drawn to scale and all capillary modules from each $\mathrm{MI}$ are not shown for the sake of clarity. Arrows represent relaxin micropipette application sites and circles represent observation sites. In this protocol, each of the relaxin micropipette application sites was observed directly ( $n=8$ for each type of arteriole). (B) The time course of the change in diameter of each vascular level in response to a 5-min application of $10^{-10} \mathrm{M}$ relaxin. *A significant increase in diameter compared with baseline for the TA and the Branch arterioles. The bracket encompasses all data that are significantly different from baseline values. (C) The peak change in diameter expressed as a per cent of maximum diameter for each vascular level in response to $10^{-10} \mathrm{M}$ relaxin. There was no significant difference in the vasodilatory response shown between the TA and Branch arterioles when comparing change in percentage maximal responses. *A significant increase in diameter compared with baseline. The bracket encompasses all data that are significantly different from baseline values.

Published by Bioscientifica Ltd. 


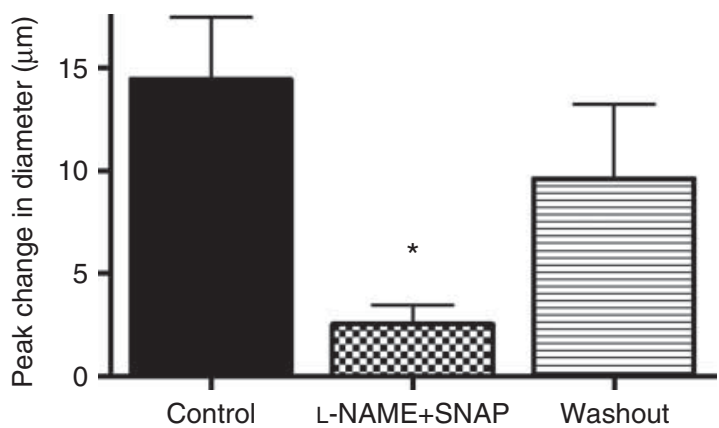

Figure 3

The effect of $10^{-5} \mathrm{M}$ L-NAME + SNAP on the peak change in diameter induced by relaxin on the TA. $10^{-10} \mathrm{M}$ relaxin produced a significant control dilation that was inhibited in the presence of $10^{-5} \mathrm{M}$ L-NAME + $10^{-7} \mathrm{M}$ SNAP $(n=8)$. Following a 30 -min washout period, the vasodilation induced by $10^{-10} \mathrm{M}$ relaxin was restored. *Significantly different values from control experiments.

washed out by 30-min superfusion with control superfusate alone. Following the washout period, $10^{-10} \mathrm{M}$ relaxin was re-applied for $5 \mathrm{~min}$ and arteriolar diameter was recorded to ensure the preparation remained responsive to relaxin.

\section{Experimental protocol 4: application of $10^{-10} \mathrm{M}$ relaxin on capillaries}

Relaxin $\left(10^{-10} \mathrm{M}\right)$ was micropipette applied to capillaries and the upstream MI arteriole responsible for perfusion of the stimulated capillaries was observed. A schematic representation of the experimental protocol is provided in Fig. 5A. During the experiment, the MI observation site was continuously recorded for $1 \mathrm{~min}$ before relaxin exposure and then continuously during the 5-min application of relaxin on the capillaries.

\section{Experimental protocol 5: $10^{-10} \mathrm{M}$ relaxin-induced conducted responses}

Micropipette application of relaxin on capillaries resulted in the upstream vasodilation of connected MI arteriole, indicating that relaxin stimulated capillaries and initiated a conducted response. To determine whether relaxin-induced conducted responses were gap junction dependent, relaxin $\left(10^{-10} \mathrm{M}\right)$ was locally micropipette applied to a TA for $5 \mathrm{~min}$ and the vasodilation at the local site was observed. After $10 \mathrm{~min}, 10^{-10} \mathrm{M}$ relaxin was re-applied to the local site for $5 \mathrm{~min}$ while observing a site $\sim 1000 \mu \mathrm{m}$ upstream along the same TA (for schematic diagram of experimental protocol 5, see Fig. 6A). A gap junction uncoupler (18- $\beta$-glycyrrhetinic acid ( $\beta G A$;
$40 \times 10^{-6} \mathrm{M}$ ) or $0.07 \%$ halothane) was then micropipette applied between the local and the upstream observation site for $30 \mathrm{~min}$ and the local relaxin application protocol was repeated, observing both the local and the upstream sites. The gap junction uncoupler application was then

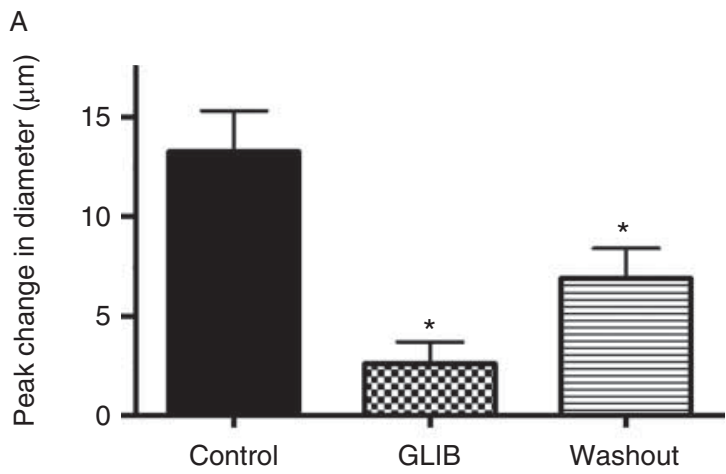

B
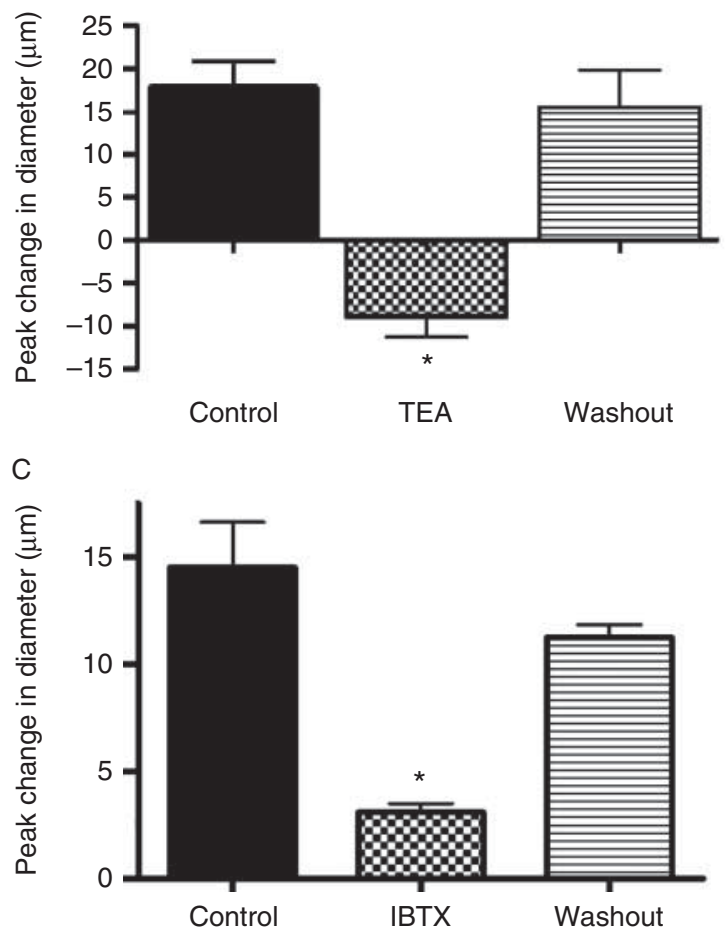

Figure 4

The effect of (A) $10^{-5} \mathrm{M}$ GLIB, (B) $10^{-3} \mathrm{M}$ TEA and (C) $10^{-7} \mathrm{M}$ IBTX on the relaxin-induced vasodilation. (A) The peak change in diameter of the TA in response to $10^{-10} \mathrm{M}$ relaxin alone (control) and in the presence of $10^{-5} \mathrm{M}$ GLIB $(n=8)$. Following a 30-min washout period, the vasodilatory response to $10^{-10} \mathrm{M}$ relaxin was returning to control values. (B) The peak change in diameter of the TA in response to $10^{-10} \mathrm{M}$ relaxin alone (control) and in the presence of $10^{-3} \mathrm{M}$ TEA $(n=8)$. Following a 1-h washout period, the vasodilatory response to $10^{-10} \mathrm{M}$ relaxin was restored. (C) The peak change in diameter of the TA in response to $10^{-10} \mathrm{M}$ relaxin alone (control) and in the presence of $10^{-7} \mathrm{M}$ IBTX $(n=8)$. Following a 30 -min washout period, the vasodilatory response to $10^{-10} \mathrm{M}$ relaxin was restored. *Significant differences from control conditions. 
stopped, and after a 30-min washout period, the relaxin application protocol was repeated for a third time to confirm that the arteriole maintained viability and responded to relaxin.

At the conclusion of protocols 1 through 5, arteriolar diameters of all observation sites were recorded following 2 min of superfusion with $10^{-4} \mathrm{M}$ sodium nitroprusside, an NO donor, which is considered to produce maximum vasodilation (Sweeney \& Sarelius 1989, Murrant \& Sarelius 2000, Mihok \& Murrant 2004). Animals were then killed with an overdose of sodium pentobarbital (33 $\mathrm{mg} / \mathrm{ml}$ i.v. to effect).

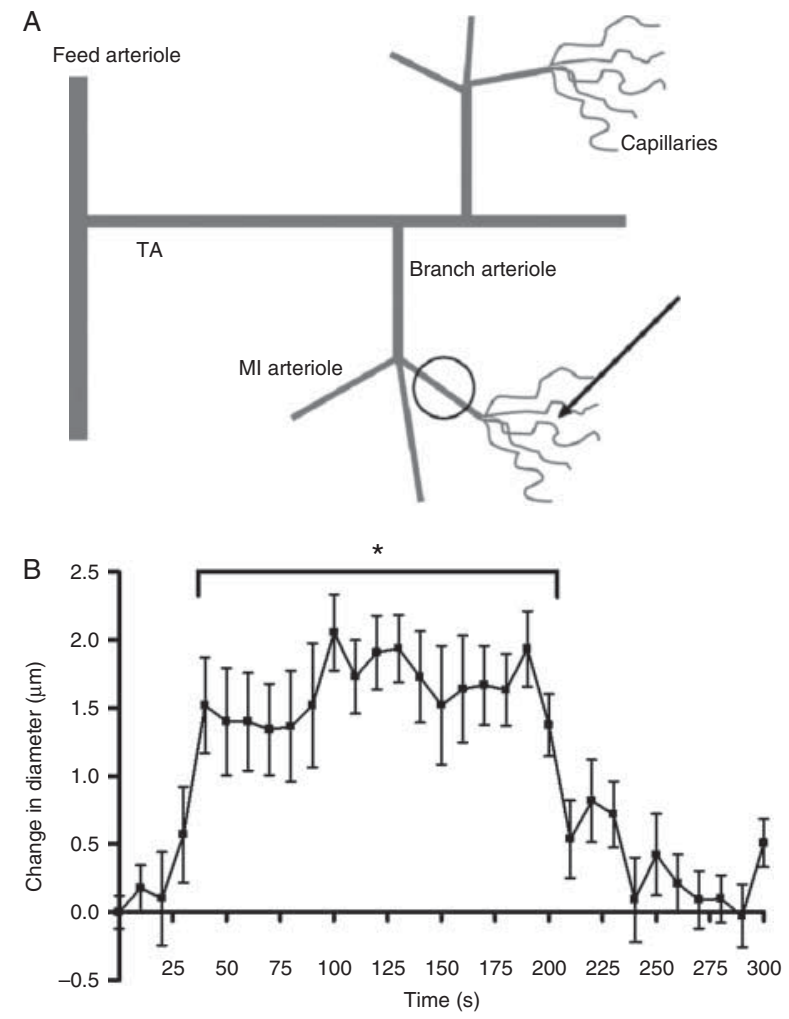

Figure 5

The peak change in diameter of the $\mathrm{MI}$ arteriole in response to relaxin applied to an associated group of capillaries. (A) A schematic representation of the branches of the terminal arteriolar microvasculature (diagram adapted from Murrant \& Sarelius (2000)). Blood flows through a subsequently diverging network of arterioles from the paired feed arterioles through the TA, Branch and $\mathrm{MI}$ arterioles until it reaches the capillary module of the network. The schematic is not drawn to scale and all capillary modules from each $\mathrm{Ml}$ are not shown for the sake of clarity. The arrows represent the relaxin micropipette application site over the capillaries and circle represents the MI observation site $(n=8)$. (B) The time course of the MI vasodilatory response to $5 \mathrm{~min}$ of $10^{-10} \mathrm{M}$ relaxin application to capillaries in the associated capillary module and observed in the $\mathrm{Ml}$ is shown. Treatment with relaxin $\left(10^{-10} \mathrm{M}\right)$ started at time zero and lasted throughout the duration of the experiment until $300 \mathrm{~s} .{ }^{*} \mathrm{~A}$ significant increase in diameter compared with baseline. The bracket encompasses all data that are significantly different from baseline values.

\section{Chemicals and reagents}

Recombinant human relaxin-2 was a generous gift from Dr E N Unemori, Corthera, Inc. Relaxin was kept in frozen aliquots and solubilised in superfusate on each experimental day. All other pharmacological agents used were obtained from Sigma-Aldrich) unless otherwise indicated and prepared on the day of the experiment.

\section{Data and statistical analysis}

All experiments were videotaped and analysed off-line. Images were digitised with Canopus Media Cruise software (Canopus Corp., San Jose, CA, USA) and arteriolar diameter was measured with calibrated ImageJ software. Arteriolar diameter was defined as the distance between each inside wall of the arteriole. Arteriolar diameter was measured just before relaxin application (defined as baseline diameter) and every $10 \mathrm{~s}$ throughout the entire 5-min application of relaxin. All data are reported as mean \pm s.E.M.; $n$ represents the number of arterioles observed. Group means were compared with a Student's t-test (Fig. 6B and C), an ANOVA (Figs 1, 2C, 3 and 4) or repeated measures ANOVA when comparing data over time (Figs $2 \mathrm{~B}$ and $5 \mathrm{~B}$ ). When the ANOVA identified a significant difference, a protected LSD was performed post hoc in order to determine whether diameter changes were significant (Snedecor \& Cochran 1989). Differences were considered statistically significant when $P<0.05$.

\section{Results}

\section{Experimental protocol 1: dose response to relaxin}

With the initial dose response range $\left(10^{-10}\right.$ to $\left.10^{-5} \mathrm{M}\right)$, all concentrations of relaxin tested produced vasodilation and peak changes in diameter that were not significantly different from each other. Thus, a second dose response using concentrations ranging from $10^{-13}$ to $10^{-8} \mathrm{M}$ was carried out. The peak changes in vessel diameter in response to $10^{-10}$ to $10^{-8} \mathrm{M}$ relaxin (concentration overlap between the two dose responses) were not significantly different between the two trials, so the data from the two trials were combined and shown in Fig. 1 (baseline diameter $=20.5 \pm 1.1 \mu \mathrm{m}$; maximum diameter $=$ $40.2 \pm 1.0 \mu \mathrm{m})$. Significant vasodilation was observed with concentrations ranging from $10^{-12}$ to $10^{-5} \mathrm{M}$, but no significant dilation was seen at $10^{-13} \mathrm{M}$. Relaxin $\left(10^{-10} \mathrm{M}\right)$ was the first concentration applied in the initial dose response and fourth concentration applied in the

Published by Bioscientifica Ltd. 
A

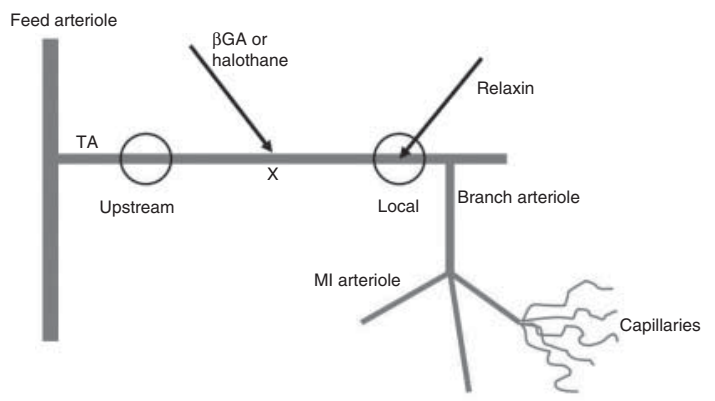

B
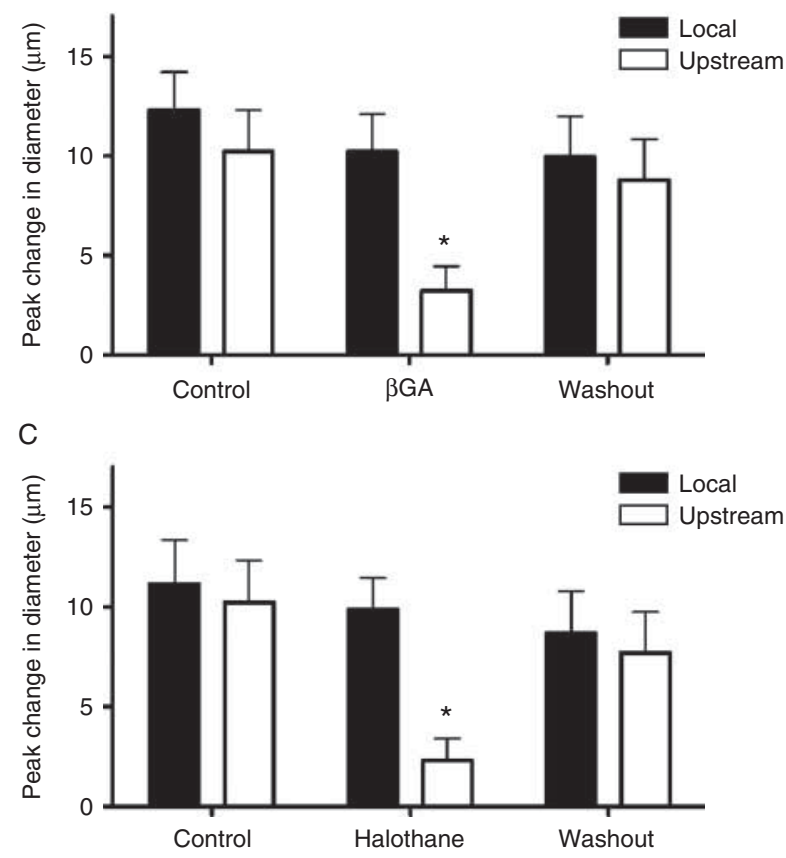

Figure 6

Uncoupling gap junctions with either $\beta G A$ or halothane significantly reduces conductance of relaxin-induced vasodilation. (A) A schematic representation of the branches of the terminal arteriolar microvasculature (diagram adapted from Murrant \& Sarelius (2000)). Blood flows through a subsequently diverging network of arterioles from the paired feed arterioles through the TA, Branch and MI arterioles until it reaches the capillary module of the network. The schematic is not drawn to scale and all capillary modules from each MI are not shown for the sake of clarity. The relaxin arrow represents the relaxin micropipette application site over the TA and circles represents local and upstream observation sites. The $\beta G A$ or Halothane arrow represents the position of the micropipette application of the gap junction uncouplers in this experiment, approximately $500 \mu \mathrm{m}$ from both the local and upstream observation sites. (B) The peak change in diameter of the local and upstream observation sites in response to locally applied $10^{-10} \mathrm{M}$ relaxin in the absence (control) and presence of gap junction inhibitor $\beta G A(n=8)$ and after washout conditions. (C) The peak change in diameter of the local and upstream sites in response to locally applied $10^{-10} \mathrm{M}$ relaxin in the absence (control) and presence of gap junction inhibitor halothane $(n=8)$ and after washout conditions.

*A significant difference from control change in diameter at the same site. second dose response; the consistency of the response at $10^{-10} \mathrm{M}$ relaxin between the two trials shows that there is no change in the sensitivity of the preparation over time or after multiple exposures to relaxin.

\section{Experimental protocol 2: effects of relaxin on different branches of the arteriolar network}

Baseline and maximal arteriolar diameters respectively for each branch order were as follows: TA, $24.2 \pm 3.1$ and $46.3 \pm 3.7 \mu \mathrm{m}(n=8)$; Branch, $13.4 \pm 2.6$ and $31.3 \pm 2.4 \mu \mathrm{m}$ $(n=8) ; \mathrm{MI}, 6.5 \pm 1.2$ and $12.1 \pm 2.1 \mu \mathrm{m} \quad(n=8)$. Relaxin $\left(10^{-10} \mathrm{M}\right)$ induced a significant vasodilation in TA and Branch arterioles; however, no significant vasodilation was observed in the MI arterioles (Fig. 2B). The absolute change in diameter of the TA appears to be larger than the Branch arteriole; however, these branch orders differ in terms of their maximum possible diameter (TA maximum diameter is $\sim 45 \mu \mathrm{m}$ and Branch arteriole maximum diameter is $\sim 30 \mu \mathrm{m}$ ) and it is important to normalise vascular responses to maximum diameter when comparing different vascular branch orders. Once normalised, there is no difference in the vasodilatory response to $10^{-10} \mathrm{M}$ relaxin between the TA and the Branch arterioles (Fig. 2C). The relaxin-induced vasodilation in both the TA and the Branch arterioles was transient, and the vasodilation was not sustained over the entire 5-min relaxin exposure period.

\section{Experimental protocol 3: involvement of NO and potassium channels in the relaxin-mediated vasodilation}

Baseline and maximal diameters for vessels studied in experimental protocol 3 are provided in Table 1 . There were no significant differences between the baseline values for control and experimental groups, indicating that there was no impact of the blockers alone on arteriolar diameter. There were no significant differences between baseline diameter in control conditions and in the presence of L-NAME + SNAP, indicating that we were successful at restoring the baseline diameter in the presence of L-NAME to control values using SNAP. Figure 3 shows that the peak change in diameter from baseline in response to $10^{-10} \mathrm{M}$ relaxin was significantly attenuated in the presence of L-NAME+SNAP. Following a 30-min washout period, the vasodilatory response to relaxin $\left(10^{-10} \mathrm{M}\right)$ was restored.

Figure 4 shows the response of relaxin in the presence of potassium channel inhibitors. Figure $4 \mathrm{~A}$ illustrates the inhibited vasodilatory response to $10^{-10} \mathrm{M}$ relaxin in the

Published by Bioscientifica Ltd 
Table 1 Baseline and maximal diameters of arterioles $(\mu \mathrm{m})$ tested in experimental protocol 3. Baseline diameters reported are baseline diameter before $10^{-10} \mathrm{M}$ relaxin application alone and baseline diameter in the presence of the pharmacological blocking agents just before $10^{-10} \mathrm{M}$ relaxin +inhibitor application. Data are presented as mean \pm s.E.M. in $\mu \mathrm{m}$

\begin{tabular}{|c|c|c|c|c|}
\hline \multirow[b]{2}{*}{ Blocker } & \multicolumn{2}{|c|}{ Baseline diameter } & \multirow[b]{2}{*}{$\begin{array}{l}\text { Maximum } \\
\text { diameter }\end{array}$} & \multirow[b]{2}{*}{$n$} \\
\hline & $\begin{array}{r}10^{-10} \mathrm{M} \text { relaxin } \\
\text { alone (control) }\end{array}$ & $\begin{array}{c}10^{-10} \mathrm{M} \text { relaxin + inhibitor } \\
\text { (experimental) }\end{array}$ & & \\
\hline L-NAME + SNAP & $15.9 \pm 1.5$ & $19.1 \pm 1.4$ & $46.1 \pm 1.6$ & 8 \\
\hline GLIB & $15.9 \pm 1.8$ & $17.4 \pm 1.5$ & $45.6 \pm 2.2$ & 8 \\
\hline TEA & $20.4 \pm 1.8$ & $24.3 \pm 1.7$ & $55.7 \pm 2.3$ & 8 \\
\hline IBTX & $17.6 \pm 1.3$ & $18.5 \pm 1.6$ & $42.5 \pm 3.2$ & 8 \\
\hline
\end{tabular}

presence of the $\mathrm{K}_{\mathrm{ATP}}$ channel blocker GLIB $\left(10^{-5} \mathrm{M}\right)$. The 30-min washout period was not long enough to fully restore the relaxin vasodilation to pre-GLIB levels but was partially restored as $10^{-10} \mathrm{M}$ relaxin produced a significantly larger dilation when compared with relaxin and $10^{-5} \mathrm{M}$ GLIB. Inhibition of $\mathrm{K}_{\mathrm{Ca}}$ channels with either $10^{-3} \mathrm{M}$ TEA (Fig. 4B) or $10^{-7} \mathrm{M}$ IBTX (Fig. 4C) significantly inhibited relaxin-induced vasodilation. Following the washout period for both inhibitors, the vasodilatory response to relaxin was restored.

\section{Experimental protocol 4: application of $10^{-10} \mathrm{M}$ relaxin on capillaries}

Application of $10^{-10} \mathrm{M}$ relaxin for $5 \mathrm{~min}$ to a group of capillaries caused a significant, transient vasodilation in the associated MI arterioles (baseline diameter: $7.2 \pm 1.3 \mu \mathrm{m}$; maximum diameter: $11.3 \pm 1.6 \mu \mathrm{m}$ ) (Fig. 5B). Significant vasodilation was observed from 50 to $200 \mathrm{~s}$ after which the arteriolar diameter returned to baseline values.

\section{Experimental protocol 5: $10^{-10} \mathrm{M}$ relaxin and conducted vasodilations}

Baseline and maximal diameters for TAs studied in protocol 5 are shown in Table 2. Application of $10^{-10} \mathrm{M}$ relaxin for $5 \mathrm{~min}$ induced a significant local vasodilation that was conducted over $1000 \mu \mathrm{m}$ to the upstream site (Fig. 6B). The magnitude of the local and upstream vasodilation did not significantly differ from each other. Application of the gap junction uncoupler $\beta$ GA (Fig. 6B) or halothane (Fig. 6C) midway between the local and upstream sites significantly inhibited the conducted vasodilation. Following a 30-min washout period, $10^{-10} \mathrm{M}$ relaxin induced a conducted vasodilation similar to control vasodilations.

\section{Discussion}

The data presented in this study show that very low concentrations of relaxin $\left(10^{-12} \mathrm{M}\right)$ produce a rapid, transient vasodilation in specific branches of the terminal arteriolar network in skeletal muscle in situ. The relaxininduced dilations in TA and Branch arterioles were both NO- and potassium channel-dependent while the smallest ramification of the arteriolar tree was not responsive to relaxin. Capillaries were also responsive to relaxin and affected the arteriolar vasculature through gap junctionmediated conducted responses. The significance of the ability of relaxin to induce conducted responses indicates that localised, paracrine release of relaxin within a tissue may have the ability to alter the tissue vascular network and significantly alter blood flow distribution within the tissue and blood flow to the tissue. The transient

Table 2 Baseline diameters, maximal diameters and distances between local and upstream sites of arterioles used in experimental protocol 5 investigating the possible role for gap junctions in transmitting vasodilation in upstream transverse arterioles in response to $10^{-10} \mathrm{M}$ relaxin. Data are mean \pm s.E.M. in $\mu \mathrm{m}$

\begin{tabular}{|c|c|c|c|c|}
\hline \multirow[b]{2}{*}{ Drug } & \multicolumn{2}{|c|}{ Control } & \multicolumn{2}{|c|}{ Blocker } \\
\hline & Local & Upstream & Local & Upstream \\
\hline$\beta G A(n=8)$ & $22.5 \pm 1.4$ & $24.3 \pm 1.1$ & $24.2 \pm 2.1$ & $25.6 \pm 3.2$ \\
\hline HAL $(n=8)$ & $19.7 \pm 0.9$ & $23.1 \pm 2.4$ & $22.4 \pm 3.1$ & $23.5 \pm 2.3$ \\
\hline
\end{tabular}

http://joe.endocrinology-journals.org DOI: 10.1530/JOE-13-0115
C 2013 Society for Endocrinology Printed in Great Britain

\begin{tabular}{|c|c|}
\hline \multicolumn{2}{|c|}{ Washout } \\
\hline Local & Upstream \\
\hline $23.1 \pm 2.2$ & $25.9 \pm 3.4$ \\
\hline $24.1 \pm 1.1$ & $25.3 \pm 2.3$ \\
\hline
\end{tabular}

\begin{tabular}{|c|c|}
\hline \multicolumn{2}{|c|}{ Maximum diameter } \\
\hline Local & Upstream \\
\hline $46.6 \pm 4.2$ & $48.6 \pm 5.2$ \\
\hline $42.5 \pm 3.9$ & $47.4 \pm 4.1$ \\
\hline
\end{tabular}


nature of the arteriolar vasodilator effect of relaxin within the skeletal muscle vascular bed indicates that relaxin's systemic haemodynamic effects are not derived through sustained changes in skeletal muscle resistance vasculature, indicating a locus of control elsewhere.

\section{Experimental considerations}

A number of factors were taken into account to ensure accurate data interpretation. These included the following: i) similar baseline diameters between control and experimental conditions were used to ensure that the experimental treatments had no effects on basal diameter of unstimulated vessels. This allows for direct comparisons to be made between control and experimental groups with pharmacological inhibitors. ii) A pharmacological agent washout process was performed after each experiment to ensure that relaxin-induced vasodilation returned. This proved that the preparation was still viable following experimental interventions and that the preparation responded to relaxin over time. iii) The maximum diameter was determined at the end of the experimental period for each experiment, which allowed us to confirm whether maximum diameter had been achieved during experimental protocols. We have previously determined that there is no difference between the maximal dilation produced by $10^{-4} \mathrm{M}$ sodium nitroprusside and a calcium-free superfusate solution (Ross et al. 2013). There was no protocol where the vasodilation induced a maximum dilation; therefore, we did not exceed maximum vasodilatory capacity of our preparation.

\section{Relaxin dose response}

Relaxin produced rapid vasodilation across a wide range of doses $\left(10^{-12}\right.$ to $\left.10^{-5} \mathrm{M}\right)$. We found that very low concentrations of relaxin $\left(10^{-12} \mathrm{M}\right)$ induced a significant vasodilation. This is an order of magnitude more sensitive than isolated resistance arterioles in which $10^{-11} \mathrm{M}$ was found to produce a significant vasodilation (Fisher et al. 2002). Relaxin $\left(10^{-12} \mathrm{M}\right)$ is well below the levels detected by ELISA and RIA techniques (Stewart et al. 1990, Gedikli et al. 2009) in the blood. It is also two to three orders of magnitude lower that the concentrations of acetylcholine (NO-dependent vasodilator) (Clark \& Fuchs 1997, Jasperse \& Laughlin 1999, Woodman et al. 2003, Spier et al. 2004, Erdei et al. 2006, Newcomer et al. 2008, Roseguini et al. 2010) and NO donors (Jasperse \& Laughlin 1999, Woodman et al. 2003, Erdei et al. 2006, Hein et al. 2010) required to initiate vasodilation.
The largest change in diameter in response to relaxin was observed at $10^{-10} \mathrm{M}$ and no larger vasodilation was observed at higher concentrations and no cumulative vasodilation was observed. This behaviour can be explained by the transient nature of the relaxin-induced vasodilation (Fig. 2B), which was observed at each concentration of relaxin used in the dose response above $10^{-12} \mathrm{M}$ (data not shown); thus, no classic 'cumulative' dose response behaviour was observed. These data indicate that, regardless of relaxin concentration above $10^{-10} \mathrm{M}$, the maximum capacity of relaxin to vasodilate is $\sim 10 \mu \mathrm{m}$. Therefore, it may not be the absolute concentration of relaxin released that is important, but the temporal release of relaxin that may establish the arteriolar vasodilatory state.

This transient vasodilatory behaviour differs from non-transient responses to relaxin found in vascular preparations such as rat renal and human subcutaneous arteries (McGuane et al. 2011), human gluteal arteries (Fisher et al. 2002), venules of the mesocaecum (Bigazzi et al. 1986) and coronary flow in the guinea pig (Bani-Sacchi et al. 1995). Thus, our data indicate that the response of the microvascular resistance arterioles of skeletal muscle may be unique and indicates that there might be compensatory mechanisms at play in restoring arterial wall diameter. Certainly, there is evidence that relaxin has specific and varied effects on different vascular beds even within the same species (Dombrowski et al. 1986, Petersen et al. 1991, Fisher et al. 2002, McGuane et al. 2011). Refractoriness to relaxin has been reported in other tissues, for example the uterus (Chamley \& Parkington 1984), the mammary gland (Summerlee et al. 1984) and the brain (Parry et al. 1990), but sustained responses have also been reported (Porter 1971, Bradshaw et al. 1981, Norstrom et al. 1984). The physiological relevance of a sustained response is self-evident, but the significance of a transient response is less obvious. Given that this transient behaviour is present in the relaxin response in other tissues indicates that there may be two common response types, transient and non-transient, each with their own, yet-to-be-determined, importance.

\section{Different microvascular responses to relaxin}

Micropipette application of $10^{-10} \mathrm{M}$ relaxin produced vasodilation when the TA, Branch arterioles and capillaries were stimulated, but no vasodilation was produced in MI arterioles when relaxin was applied directly. These data indicate that a relaxin membrane receptor population (RXFP1) is present at the TA, Branch and capillary

Published by Bioscientifica Ltd 
level but not on MI arterioles. There is evidence to support that RXFP1 is located on the endothelium of renal arteries (Novak et al. 2006) and VSM of renal (Novak et al. 2006) and cardiac tissues (Samuel et al. 2003). Studies on isolated vessels have shown that the endothelium is necessary for vasodilation by relaxin in gluteal and subcutaneous arteries (Fisher et al. 2002, McGuane et al. 2011). It is unclear from our studies whether RXFP1 is present on the VSM, endothelium or both in skeletal muscle resistance arterioles. The capillary response to relaxin provides evidence that implies that capillary endothelial cells express a membrane receptor population for relaxin. There is always a remote possibility that there are indirect effects of relaxin (non-receptor-mediated effects) on the vasculature, but the lack of effect of relaxin on the MI would indicate that there are no indirect effects. Our data show that, although the MI does not respond to relaxin directly, they can respond to relaxin indirectly, through capillary stimulation and conducted responses.

Our data show that the arteriolar vasodilation in response to relaxin was dependent on NO. Previous reports have indicated that relaxin simulates NOmediated responses in multiple vascular and non-vascular tissues (Bani et al. 1995, Bani-Sacchi et al. 1995, Novak et al. 2002, Failli et al. 2005, McGuane et al. 2011, van Drongelen 2011). Our data show that TA and Branch arterioles dilate to the same extent relaxin, once the maximum size of the vessels is taken into account; however, MI arterioles do not respond directly to relaxin. As mentioned earlier, this could be due to the lack of the membrane receptor population for relaxin. A second possibility is that there is a reduced importance of NO in the terminal microvasculature tree as vessels branch toward the capillaries. Hester et al. (1993) showed that even though all the arterioles in the terminal microvasculature have the ability to produce $\mathrm{NO}$ and respond to it, the importance of $\mathrm{NO}$ in their function is less as the branch order gets smaller. Thus, the importance of NO in the regulation of MI diameter may be diminished, therefore possibly less responsive to NO-dependent dilators such as relaxin.

We have further demonstrated that relaxin causes vasodilation through $\mathrm{K}_{\mathrm{ATP}}$ and $\mathrm{K}_{\mathrm{Ca}}$ channels. Potassium channels have been implicated in many vasodilatory responses in the microcirculation by inducing hyperpolarisation and relaxing vascular smooth muscle (for review see Jackson (2005)). We show that this is consistent within the relaxin-induced stimulation of the vasculature of skeletal muscle arterioles. Whether NO stimulates the opening of the potassium channels is unknown. There is support for $\mathrm{NO}$ and cGMP in opening $\mathrm{K}_{\mathrm{ATP}}$ channels (Murphy \& Brayden 1995) and support for NO in stimulating $\mathrm{K}_{\mathrm{Ca}}$ channels (Archer et al. 1994), but the exact signalling mechanisms for relaxin in skeletal muscle arterioles are yet to be defined. McGuane et al. (2011) have shown that phosphatidylinositol-3-kinase and Akt are part of the relaxin signalling pathway to stimulate rapid vasodilation but, as of yet, the connection with potassium channels has not been made.

\section{Relaxin-induced conducted responses}

Capillary stimulation with relaxin produced vasodilation in the upstream MI, indicating that relaxin can induce conducted responses. We explored the nature of the conducted responses induced by relaxin at the level of the TA and found that, indeed, relaxin induced gap junction-dependent conducted responses. We demonstrated that $10^{-10} \mathrm{M}$ relaxin, applied locally to the arteriole, could induce dilation to a remote site, over $1000 \mu \mathrm{m}$ upstream of the site of stimulation, and that the dilation at the remote site could be inhibited by two non-specific gap junction uncouplers, $\beta G A$ and halothane. In the microcirculation, gap junctions are primarily composed of connexin $(\mathrm{Cx})$ proteins, specifically CX37 (GJA4), CX40 (GJA5) and CX43 (GJA1) (Little et al. 1995, Gustafsson et al. 2003, Looft-Wilson et al. 2004a,b, Hakim et al. 2008). Currently, there are no tools to block gap junctions of a specific $\mathrm{Cx}$ isoform, only non-specific gap junction uncouplers such as the ones used in this study. The vasodilatory signal conducted through the gap junction connections is thought to be hyperpolarisation, although there are reports of various small molecules being able to traverse gap junctions (such as $\mathrm{Ca}^{++}$and $\mathrm{IP}_{3}$ (Evans \& Martin 2002, Saez et al. 2003)). We have shown that relaxin vasodilates through $\mathrm{K}_{\mathrm{ATP}}$ and $\mathrm{K}_{\mathrm{Ca}}$ channels, therefore exhibiting the potential to initiate hyperpolarisation that may be transmitted longitudinally throughout the vascular network.

Conducted responses play an important physiological role in the coordinated distribution of blood flow to tissues and within tissues, ensuring adequate perfusion to tissues during times of increased metabolic demand. Conducted responses have been well characterised in skeletal muscle in response to both application of pharmacological dilatory substances (e.g. acetylcholine) (for example, Segal \& Duling $(1986,1989))$ and during skeletal muscle contraction (Berg et al. 1997, Murrant \& Sarelius 2000). During skeletal muscle contraction, dilatory substances are released by active skeletal muscle, which stimulate the

Published by Bioscientifica Ltd. 
vasculature and initiate conducted responses and signal upstream arterioles to vasodilate to increase tissue perfusion to the active skeletal muscle cells. Therefore, locally produced signals have the capacity to alter remote sites of the tissue vascular network to enhance tissue blood flow. It is possible that local production of relaxin within a tissue may act to enhance the response of the tissue vascular network and alter tissue blood flow. For example, during pregnancy in the myometrium, following implantation, locally produced relaxin has been demonstrated to be a critical step to implantation events and the stimulation of angiogenesis (Einspanier 2001, Goldsmith et al. 2004). Relaxin may enhance blood flow to this tissue during pregnancy through conducted responses. Finally, the propagation of vasodilation along arterioles may occur in tumours where relaxin has been demonstrated to be up-regulated (e.g. prostate and breast, Binder et al. (2002) and Silvertown et al. (2006)). The enhancement of blood flow to tumours is a critical step in the growth of cancer, and given that relaxin is locally produced in some tumours (Silvertown et al. 2006), relaxin-induced conducted vasodilation may act to enhance tumour blood flow. Given that the functional concentration of relaxin is very low, it is now critical to understand the local concentrations and release sites of relaxin in order to fully understand its potential for affecting tissue blood flow. This is especially important as the list of sources of relaxin continues to grow from the ovaries, decidua, placenta and prostate (Bani 1997) to include the left ventricle and atria (Dschietzig et al. 2001).

\section{Summary}

Our data show that low concentrations of relaxin exhibit a differential ability to induce transient vasodilations in various levels of the terminal microvasculature of skeletal muscle in situ through NO- and potassium channeldependent mechanisms. The transient nature of the arteriolar vasodilation in skeletal muscle in response to relaxin raises questions as to the role of relaxin in affecting sustained changes in total peripheral resistance and its contribution to sustained systemic haemodynamic changes (Conrad et al. 2004) and suggests that the locus of control of sustained haemodynamic changes due to relaxin resides elsewhere.

Conducted responses initiated by relaxin at both the capillary and the arteriolar level of the microvasculature introduces a new potential mechanism by which relaxin may alter blood flow to a tissue and alter blood flow distribution within a tissue. The ability of relaxin to induce conducted responses indicates that small, localised release of relaxin within a tissue will be able to affect remote regions of the tissue microvasculature and change blood flow distribution within a tissue, and if the vasodilation is large enough, it will even change blood flow to the tissue itself.

\section{Declaration of interest}

The authors declare that there is no conflict of interest that could be perceived as prejudicing the impartiality of the research reported.

\section{Funding}

The authors wish to acknowledge funding to CLM from NSERC Canada (\#400351, 2009-2014) and to AJSS from the University of Guelph.

\section{References}

Anwer K, Oberti C, Perez GJ, Perez-Reyes N, McDougall JK, Monga M, Sanborn BM, Stefani E \& Toro L 1993 Calcium-activated $\mathrm{K}^{+}$channels as modulators of human myometrial contractile activity. American Journal of Physiology 265 C976-C985.

Archer SL, Huang JM, Hampl V, Nelson DP, Shultz PJ \& Weir EK 1994 Nitric oxide and cGMP cause vasorelaxation by activation of a charybdotoxin-sensitive K channel by cGMP-dependent protein kinase. PNAS 91 7583-7587. (doi:10.1073/pnas.91.16.7583)

Armstrong ML, Dua AK \& Murrant CL 2007 Potassium initiates vasodilatation induced by a single skeletal muscle contraction in hamster cremaster muscle. Journal of Physiology 581 841-852. (doi:10.1113/jphysiol.2007.130013)

Baez S 1973 An open cremaster muscle preparation for the study of blood vessels by in vivo microscopy. Microvascular Research 5 384-394. (doi:10.1016/0026-2862(73)90054-X)

Bani D 1997 Relaxin: a pleiotropic hormone. General Pharmacology 28 13-22. (doi:10.1016/S0306-3623(96)00171-1)

Bani D, Masini E, Bello MG, Bigazzi M \& Sacchi TB 1995 Relaxin activates the L-arginine-nitric oxide pathway in human breast cancer cells. Cancer Research 55 5272-5275.

Bani D, Failli P, Bello MG, Thiemermann C, Bani Sacchi T, Bigazzi M \& Masini E 1998 Relaxin activates the L-arginine-nitric oxide pathway in vascular smooth muscle cells in culture. Hypertension 31 1240-1247. (doi:10.1161/01.HYP.31.6.1240)

Bani-Sacchi T, Bigazzi M, Bani D, Mannaioni PF \& Masini E 1995 Relaxin-induced increased coronary flow through stimulation of nitric oxide production. British Journal of Pharmacology 116 1589-1594. (doi:10.1111/j.1476-5381.1995.tb16377.x)

Bathgate RA, Ivell R, Sanborn BM, Sherwood OD \& Summers RJ 2006 International Union of Pharmacology LVII: recommendations for the nomenclature of receptors for relaxin family peptides. Pharmacological Reviews 58 7-31. (doi:10.1124/pr.58.1.9)

Berg BR, Cohen KD \& Sarelius IH 1997 Direct coupling between blood flow and metabolism at the capillary level in striated muscle. American Journal of Physiology 272 H2693-H2700.

Bigazzi M, Del Mese A, Petrucci F, Casali R \& Novelli GP 1986 The local administration of relaxin induces changes in the microcirculation of the rat mesocaecum. Acta Endocrinologica 112 296-299. (doi:10.1530/ acta.0.1120296)

Binder C, Hagemann T, Husen B, Schulz M \& Einspanier A 2002 Relaxin enhances in-vitro invasiveness of breast cancer cell lines by up- http://joe.endocrinology-journals.org DOI: 10.1530/JOE-13-0115 (c) 2013 Society for Endocrinology Printed in Great Britain 
regulation of matrix metalloproteases. Molecular Human Reproduction $\mathbf{8}$ 789-796. (doi:10.1093/molehr/8.9.789)

Bradshaw JM, Downing SJ, Moffatt A, Hinton JC \& Porter DG 1981 Demonstration of some of the physiological properties of rat relaxin. Journal of Reproduction and Fertility 63 145-153. (doi:10.1530/jrf.0. 0630145)

Chamley WA \& Parkington HC 1984 Relaxin inhibits the plateau component of the action potential in the circular myometrium of the rat. Journal of Physiology 353 51-65.

Clark SG \& Fuchs LC 1997 Role of nitric oxide and $\mathrm{Ca}^{++}$-dependent $\mathrm{K}^{+}$ channels in mediating heterogeneous microvascular responses to acetylcholine in different vascular beds. Journal of Pharmacology and Experimental Therapeutics 282 1473-1479.

Conrad KP, Debrah DO, Novak J, Danielson LA \& Shroff SG 2004 Relaxin modifies systemic arterial resistance and compliance in conscious, nonpregnant rats. Endocrinology 145 3289-3296. (doi:10.1210/ en.2003-1612)

Danielson LA \& Conrad KP 1995 Acute blockade of nitric oxide synthase inhibits renal vasodilation and hyperfiltration during pregnancy in chronically instrumented conscious rats. Journal of Clinical Investigation 96 482-490. (doi:10.1172/JCI118059)

Danielson LA, Sherwood OD \& Conrad KP 1999 Relaxin is a potent renal vasodilator in conscious rats. Journal of Clinical Investigation 103 525-533. (doi:10.1172/JCI5630)

Dombrowski MP, Savoy-Moore RT, Swartz K, Churchill PC, Mariona FG, Greenwood FC, Bryant-Greenwood GD \& Evans MI 1986 Effect of porcine relaxin on the human umbilical artery. Journal of Reproductive Medicine 31 467-472.

van Drongelen J, Ploemen IH, Pertijs J, Gooi JH, Sweep FC, Lotgering FK, Spaanderman ME \& Smits P 2011 Aging attenuates the vasodilator response to relaxin. American Journal of Physiology. Heart and Circulatory Physiology 300 H1609-H1615.

Dschietzig T, Richter C, Bartsch C, Laule M, Armbruster FP, Baumann G \& Stangl K 2001 The pregnancy hormone relaxin is a player in human heart failure. FASEB Journal 15 2187-2195. (doi:10.1096/fj.010070com)

Dua AK, Dua N \& Murrant CL 2009 Skeletal muscle contraction-induced vasodilator complement production is dependent on stimulus and contraction frequency. American Journal of Physiology. Heart and Circulatory Physiology 297 H433-H442. (doi:10.1152/ajpheart. 00216.2009)

Einspanier A 2001 Relaxin is an important factor for uterine differentiation and implantation in the marmoset monkey. In Relaxin 2000: Proceedings of the 3rd International Conference on Relaxin \& Related Peptides, pp73-82. Eds G.W.Tregear, R.Ivell, R.Bathgate, J.D. Wade. Dordrecht, Netherlands: Kluwer Academic Publishers.

Erdei N, Toth A, Pasztor ET, Papp Z, Edes I, Koller A \& Bagi Z 2006 High-fat diet-induced reduction in nitric oxide-dependent arteriolar dilation in rats: role of xanthine oxidase-derived superoxide anion. American Journal of Physiology. Heart and Circulatory Physiology 291 H2107-H2115. (doi:10.1152/ajpheart.00389.2006)

Evans WH \& Martin PE 2002 Gap junctions: structure and function (Review). Molecular Membrane Biology 19 121-136. (doi:10.1080/ 09687680210139839)

Failli P, Nistri S, Mazzetti L, Chiappini L \& Bani D 2005 Effects of relaxin on vascular smooth muscle and endothelial cells in normotensive and hypertensive rats. Annals of the New York Academy of Sciences 1041 311-313. (doi:10.1196/annals.1282.048)

Fisher C, MacLean M, Morecroft I, Seed A, Johnston F, Hillier C \& McMurray J 2002 Is the pregnancy hormone relaxin also a vasodilator peptide secreted by the heart? Circulation 106 292-295. (doi:10.1161/ 01.CIR.0000025630.05387.45)

Folkow B, Karlstrom G, Nilsson H \& Sjoblom N 1984 How do changes in diameter at the precapillary level affect cardiovascular function? Journal of Cardiovascular Pharmacology 6(Suppl 2) S280-S288. (doi:10.1097/00005344-198406002-00002)
Frame MD \& Sarelius IH 1993 Regulation of capillary perfusion by small arterioles is spatially organized. Circulation Research 73 155-163. (doi:10.1161/01.RES.73.1.155)

Gedikli O, Yilmaz H, Kiris A, Karaman K, Ozturk S, Baykan M, Ucar U, Durmus I, Karahan C \& Celik S 2009 Circulating levels of relaxin and its relation to cardiovascular function in patients with hypertension. Blood Pressure 18 68-73. (doi:10.1080/08037050902864086)

Goldsmith LT, Weiss G, Palejwala S, Plant TM, Wojtczuk A, Lambert WC, Ammur N, Heller D, Skurnick JH, Edwards D et al. 2004 Relaxin regulation of endometrial structure and function in the rhesus monkey. PNAS 101 4685-4689. (doi:10.1073/pnas.0400776101)

Gorczynski RJ, Klitzman B \& Duling BR 1978 Interrelations between contracting striated muscle and precapillary microvessels. American Journal of Physiology 235 H494-H504.

Gustafsson F, Mikkelsen HB, Arensbak B, Thuneberg L, Neve S, Jensen LJ \& Holstein-Rathlou NH 2003 Expression of connexin 37, 40 and 43 in rat mesenteric arterioles and resistance arteries. Histochemistry and Cell Biology 119 139-148. (doi:10.1007/s00418-002-0493-0)

Haddy FJ, Overbeck HW \& Daugherty RM Jr 1968 Peripheral vascular resistance. Annual Review of Medicine 19 167-194. (doi:10.1146/ annurev.me.19.020168.001123)

Hakim CH, Jackson WF \& Segal SS 2008 Connexin isoform expression in smooth muscle cells and endothelial cells of hamster cheek pouch arterioles and retractor feed arteries. Microcirculation 15 503-514. (doi:10.1080/10739680801982808)

Hein TW, Rosa RH Jr, Yuan Z, Roberts E \& Kuo L 2010 Divergent roles of nitric oxide and rho kinase in vasomotor regulation of human retinal arterioles. Investigative Ophthalmology \& Visual Science 51 1583-1590. (doi:10.1167/iovs.09-4391)

Hester RL, Eraslan A \& Saito Y 1993 Differences in EDNO contribution to arteriolar diameters at rest and during functional dilation in striated muscle. American Journal of Physiology 265 H146-H151.

Jackson WF 1993 Regional differences in mechanism of action of oxygen on hamster arterioles. American Journal of Physiology 265 H599-H603.

Jackson WF 2005 Potassium channels in the peripheral microcirculation. Microcirculation 12 113-127. (doi:10.1080/10739680590896072)

Jackson WF \& Blair KL 1998 Characterization and function of $\mathrm{Ca}(2+)$ activated $\mathrm{K}^{+}$channels in arteriolar muscle cells. American Journal of Physiology 274 H27-H34.

Jasperse JL \& Laughlin MH 1999 Vasomotor responses of soleus feed arteries from sedentary and exercise-trained rats. Journal of Applied Physiology 86 441-449.

Little TL, Beyer EC \& Duling BR 1995 Connexin 43 and connexin 40 gap junctional proteins are present in arteriolar smooth muscle and endothelium in vivo. American Journal of Physiology 268 H729-H739.

Looft-Wilson RC, Haug SJ, Neufer PD \& Segal SS 2004a Independence of connexin expression and vasomotor conduction from sympathetic innervation in hamster feed arteries. Microcirculation 11 397-408. (doi:10.1080/10739680490457782)

Looft-Wilson RC, Payne GW \& Segal SS 2004b Connexin expression and conducted vasodilation along arteriolar endothelium in mouse skeletal muscle. Journal of Applied Physiology 97 1152-1158. (doi:10.1152/ japplphysiol.00133.2004)

McGuane JT, Debrah JE, Sautina L, Jarajapu YP, NovakJ, Rubin JP, Grant MB, Segal M \& Conrad KP 2011 Relaxin induces rapid dilation of rodent small renal and human subcutaneous arteries via PI3 kinase and nitric oxide. Endocrinology 152 2786-2796. (doi:10.1210/en.2010-1126)

Meera P, Anwer K, Monga M, Oberti C, Stefani E, Toro L \& Sanborn BM 1995 Relaxin stimulates myometrial calcium-activated potassium channel activity via protein kinase A. American Journal of Physiology 269 C312-C317.

Meininger GA 1987 Responses of sequentially branching macroand microvessels during reactive hyperemia in skeletal muscle. Microvascular Research 34 29-45. (doi:10.1016/0026-2862(87)90077-X)

Metra M, TeerlinkJR, Felker GM, Greenberg BH, Filippatos G, Ponikowski P, Teichman SL, Unemori E, Voors AA, Weatherley BD et al. 2010 Dyspnoea 
and worsening heart failure in patients with acute heart failure: results from the Pre-RELAX-AHF study. European Journal of Heart Failure 12 1130-1139. (doi:10.1093/eurjhf/hfq132)

Mihok ML \& Murrant CL 2004 Rapid biphasic arteriolar dilations induced by skeletal muscle contraction are dependent on stimulation characteristics. Canadian Journal of Physiology and Pharmacology 82 282-287. (doi:10.1139/y04-016)

Murphy ME \& Brayden JE 1995 Nitric oxide hyperpolarizes rabbit mesenteric arteries via ATP-sensitive potassium channels. Journal of Physiology 486 47-58.

Murrant CL 2005 Stimulation characteristics that determine arteriolar dilation in skeletal muscle. American Journal of Physiology. Regulatory, Integrative and Comparative Physiology 289 R505-R513. (doi:10.1152/ ajpregu.00571.2004)

Murrant CL \& Sarelius IH 2000 Local and remote arteriolar dilations initiated by skeletal muscle contraction. American Journal of Physiology. Heart and Circulatory Physiology 279 H2285-H2294.

Murrant CL \& Sarelius IH 2002 Multiple dilator pathways in skeletal muscle contraction-induced arteriolar dilations. American Journal of Physiology. Regulatory, Integrative and Comparative Physiology 282 R969-R978.

Newcomer SC, Taylor JC, McAllister RM \& Laughlin MH 2008 Effects of chronic nitric oxide synthase inhibition on endothelium-dependent and -independent relaxation in arteries that perfuse skeletal muscle of swine. Endothelium 15 17-31. (doi:10.1080/10623320802092211)

Norstrom A, Bryman I, Wiqvist N, Sahni S \& Lindblom B 1984 Inhibitory action of relaxin on human cervical smooth muscle. Journal of Clinical Endocrinology and Metabolism 59 379-382. (doi:10.1210/jcem-59-3-379)

Novak J, Ramirez RJ, Gandley RE, Sherwood OD \& Conrad KP 2002 Myogenic reactivity is reduced in small renal arteries isolated from relaxin-treated rats. American Journal of Physiology. Regulatory, Integrative and Comparative Physiology 283 R349-R355. (doi:10.1152/ajpregu. 00635.200)

Novak J, Parry LJ, Matthews JE, Kerchner LJ, Indovina K, Hanley-Yanez K, Doty KD, Debrah DO, Shroff SG \& Conrad KP 2006 Evidence for local relaxin ligand-receptor expression and function in arteries. FASEB Journal 20 2352-2362. (doi:10.1096/fj.06-6263com)

Parry LJ, Poterski RS, Summerlee AJ \& Jones SA 1990 Mechanism of the haemotensive action of porcine relaxin in anaesthetized rats. Journal of Neuroendocrinology 2 53-58. (doi:10.1111/j.1365-2826.1990.tb00392.x)

Petersen LK, Svane D, Uldbjerg N \& Forman A 1991 Effects of human relaxin on isolated rat and human myometrium and uteroplacental arteries. Obstetrics and Gynecology 78 757-762.

Piedras-Renteria ES, Sherwood OD \& Best PM 1997 Effects of relaxin on rat atrial myocytes. I. Inhibition of I(to) via PKA-dependent phosphorylation. American Journal of Physiology 272 H1791-H1797.

Porter DG 1971 The action of relaxin on myometrial activity in the guineapig in vivo. Journal of Reproduction and Fertility 26 251-253. (doi:10.1530/ jrf.0.0260251)

Roseguini BT, Davis MJ \& Harold Laughlin M 2010 Rapid vasodilation in isolated skeletal muscle arterioles: impact of branch order. Microcirculation 17 83-93. (doi:10.1111/j.1549-8719.2009.00005.x)

Ross GA, Mihok ML \& Murrant CL 2013 Extracellular adenosine initiates rapid arteriolar vasodilation induced by a single skeletal muscle contraction in hamster cremaster muscle. Acta Physiologica 208 74-87. (doi:10.1111/apha.12060)

Saez JC, Berthoud VM, Branes MC, Martinez AD \& Beyer EC 2003 Plasma membrane channels formed by connexins: their regulation and functions. Physiological Reviews 83 1359-1400. (doi:10.1152/physrev. 00007.2003)

Samuel CS, Tian H, Zhao L \& Amento EP 2003 Relaxin is a key mediator of prostate growth and male reproductive tract development. Laboratory Investigation 83 1055-1067. (doi:10.1097/01.LAB. 0000079784.81186.B9)

Sarelius IH, Maxwell LC, Gray SD \& Duling BR 1983 Capillarity and fiber types in the cremaster muscle of rat and hamster. American Journal of Physiology 245 H368-H374.

Segal SS 2005 Regulation of blood flow in the microcirculation. Microcirculation 12 33-45. (doi:10.1080/10739680590895028)

Segal SS \& Duling BR 1986 Flow control among microvessels coordinated by intercellular conduction. Science 234 868-870. (doi:10.1126/science. 3775368)

Segal SS \& Duling BR 1989 Conduction of vasomotor responses in arterioles: a role for cell-to-cell coupling? American Journal of Physiology 256 H838-H845.

Silvertown JD, Ng J, Sato T, Summerlee AJ \& Medin JA 2006 H2 relaxin overexpression increases in vivo prostate xenograft tumor growth and angiogenesis. International Journal of Cancer 118 62-73. (doi:10.1002/ ijc.21288)

Snedecor GW \& Cochran WG 1989 Statistical Methods. edn 8, pp 212-235. Eds GW Snedecor \& WG Cochran. Ames, IA: Iowa State University Press.

Spier SA, Delp MD, Meininger CJ, Donato AJ, Ramsey MW \& Muller-Delp JM 2004 Effects of ageing and exercise training on endothelium-dependent vasodilatation and structure of rat skeletal muscle arterioles. Journal of Physiology 556 947-958. (doi:10.1113/jphysiol.2003.060301)

Stewart DR, Celniker AC, Taylor CA Jr, Cragun JR, Overstreet JW \& Lasley BL 1990 Relaxin in the peri-implantation period. Journal of Clinical Endocrinology and Metabolism 70 1771-1773. (doi:10.1210/ jcem-70-6-1771)

Summerlee AJ, O’Byrne KT, Paisley AC, Breeze MF \& Porter DG 1984 Relaxin affects the central control of oxytocin release. Nature 309 372-374. (doi:10.1038/309372a0)

Sweeney TE \& Sarelius IH 1989 Arteriolar control of capillary cell flow in striated muscle. Circulation Research 64 112-120. (doi:10.1161/ 01.RES.64.1.112)

Teerlink JR, Metra M, Felker GM, Ponikowski P, Voors AA, Weatherley BD, Marmor A, Katz A, Grzybowski J, Unemori E et al. 2009 Relaxin for the treatment of patients with acute heart failure (Pre-RELAX-AHF): a multicentre, randomised, placebo-controlled, parallel-group, dose-finding phase IIb study. Lancet 373 1429-1439. (doi:10.1016/ S0140-6736(09)60622-X)

Teichman SL, Unemori E, Teerlink JR, Cotter G \& Metra M 2010 Relaxin: review of biology and potential role in treating heart failure. Current Heart Failure Reports 7 75-82. (doi:10.1007/s11897-010-0010-z)

Twynstra J, Ruiz DA \& Murrant CL 2012 Functional coordination of the spread of vasodilations through skeletal muscle microvasculature: implications for blood flow control. Acta Physiologica 206 229-241. (doi:10.1111/j.1748-1716.2012.02465.x)

Woodman CR, Price EM \& Laughlin MH 2003 Selected Contribution: aging impairs nitric oxide and prostacyclin mediation of endotheliumdependent dilation in soleus feed arteries. Journal of Applied Physiology 95 2164-2170. (doi:10.1152/japplphysiol.01073.2002)

Received in final form 21 May 2013

Accepted 28 May 2013

Accepted Preprint published online 28 May 2013 http://joe.endocrinology-journals.org DOI: 10.1530/JOE-13-0115
() 2013 Society for Endocrinology Printed in Great Britain 